\title{
Cross-Sectional and Longitudinal Associations between Leisure Time Physical Activity, Mental Well-Being and Subjective Health in Middle Adulthood
}

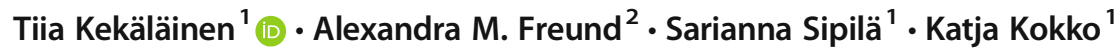

Received: 23 August 2018 / Accepted: 8 March 2019/ Published online: 21 March 2019

(C) The Author(s) 2019

\begin{abstract}
Previous studies have shown that participation in leisure time physical activity is related to better mental well-being and subjective health. However, the associations between different types of leisure time physical activities and different dimensions of mental well-being have rarely been studied. In addition, longitudinal research, analyzing possible causal relations between these variables, is lacking. To investigate these research questions, data gathered at ages 42 and 50 (present $N=303$ ) for the Finnish Jyväskylä Longitudinal Study of Personality and Social Development were used. Physical activity was assessed as frequency of participation at ages 42 and 50, and at age 50 also as frequency of participation in different types of physical activities. Mental well-being was captured by emotional, psychological and social well-being and subjective health by self-rated health and symptoms. Crosssectionally, different types of physical activities were related to different dimensions of well-being. Walking had positive associations with psychological and social well-being, rambling in nature with emotional and social well-being, and endurance training with subjective health. Rambling in nature was also positively related to subjective health but only among men. Longitudinally, mental well-being predicted later participation in leisuretime physical activity, whereas no longitudinal associations between subjective health and physical activity were found. The results suggest that leisure time physical activities are related to current mental well-being and subjective health in midlife. Across time, good mental well-being seems to be a resource promoting engagement in physical activity.
\end{abstract}

Electronic supplementary material The online version of this article (https://doi.org/10.1007/s11482-01909721-4) contains supplementary material, which is available to authorized users.

Tiia Kekäläinen

tiia.m.kekalainen@jyu.fi

1 Gerontology Research Center and Faculty of Sport and Health Sciences, University of Jyväskylä, Box 35, 40014 Jyväskylä, PO, Finland

2 Department of Psychology and University Priority Program "Dynamics of Healthy Aging”, University of Zurich, Binzmühlestrasse 14, Box 11, CH-8050 Zurich, Switzerland 
Keywords Physical activity $\cdot$ Exercise $\cdot$ Well-being $\cdot$ Midlife

\section{Introduction}

\section{The Concept of Well-Being in this Study}

The term well-being is often used in the psychological literature but is defined in different ways in different research traditions. Here, we refer to well-being as a subjective experience and conceptualize it using the tripartite model proposed by Keyes (2005), according to which mental well-being is not understood simply as the absence of ill-being (Keyes 2005; Ryan and Deci 2001; Seligman 2008). Instead, individuals with high well-being are flourishing and have high levels of emotional, psychological and social well-being (Keyes 2005). Emotional well-being describes an individual's emotional states and cognitive evaluation of satisfaction with life, including the presence of positive feelings, absence of negative feelings and overall perceived satisfaction with life (Keyes 2005). Psychological well-being indicates positive functioning in six domains: self-acceptance, positive relations with others, personal growth, purpose in life, environmental mastery and autonomy (Ryff 1989). Social well-being, measured along the dimensions of coherence, actualization, integration, acceptance and contribution, indicates how well an individual is functioning as a part of society and in meeting social challenges (Keyes 1998). Here, in line with other research based on the same Finnish JYLS data (Kokko et al. 2013a; Kokko et al. 2015), we use the term mental wellbeing as defined in the Keyes' tripartite model (Keyes 2005).

Because leisure time physical activity (LTPA) has both mental and physical benefits (McAuley and Rudolp 1995; Netz et al. 2005; Newman et al. 2014), as well as applying the tripartite model of mental well-being, subjective health is also investigated in this study. Subjective health includes the absence of bothersome symptoms but, like mental well-being, it is not merely the absence of ill-being: subjective health also has a positive side, manifested in experiences such as a sense of energy, vitality and overall physical well-being (Seligman 2008). In the present study, we include self-rated health and symptoms as indicators of subjective health (Kinnunen et al. 2005).

\section{Leisure Time Physical Activity and Well-Being}

Leisure is one of the life domains considered central for overall well-being (Diener et al. 1999; Nawijn and Veenhoven 2013). Nowadays, when most jobs are sedentary, LTPA plays a key role in the recuperation of both mind and body. Sedentary leisure behavior is negatively associated with mental well-being and subjective health outcomes (deRezende et al. 2014; Hamer et al. 2010), while numerous previous studies conducted in different fields have shown a positive association of LTPA with mental well-being and health among different age groups, including middle-aged adults (Brown et al. 2000; Holstila et al. 2017; Lahti et al. 2016; Penedo and Dahn 2005; Södergren et al. 2008; Sonnentag 2003; Wiese et al. 2018). The possible reasons why LTPA contributes to mental well-being and subjective health include, physical benefits, mastery experiences gained during exercise, positive experiences of recovery and relaxation, and social interaction (McAuley and Rudolp 1995; Netz et al. 2005; Newman et al. 2014).

Previous studies have mainly focused on general LTPA. However, different types of LTPA have different general characteristics, such as where (outdoor vs. indoor), with 
whom (social vs. solitary), and how intensively (more vs. less intensive) they are performed. In addition, different types of LTPA, such as endurance training and gym training, target different physical characteristics (Garber et al. 2011) and may, therefore, also have different psychological benefits. Previous reviews have shown that both endurance and resistance training are related to mental well-being among adults in all age groups (O'Connor et al. 2010; Penedo and Dahn 2005). In addition, cross-sectional studies have consistently found positive associations between different types of LTPA (e.g. walking, outdoor and indoor activities) and mental well-being or subjective health among different adult age groups (Chang et al. 2018; Oh et al. 2017; Pietilä et al. 2015).

Some studies have also found differences between different types of LTPA in relation to well-being. A study comparing adults' (age 20-65) favorite types of sports and perceived stress levels found some differences between individuals' LTPA preferences: for example, among women, those who preferred walking or meditation perceived higher levels of stress than those who preferred other types of LTPA, such as biking, fitness or dance, and among men, those who preferred ball games perceived lower levels of stress than those who preferred other types of LTPA (Asztalos et al. 2012). There is also some evidence from samples of young adults and of adults in general of higher well-being among those who participate in team sports or sport clubs than those who participate in individual LTPA (Andersen et al. 2018; Doré et al. 2016; Eime et al. 2010). Intensity has shown a linear relationship with subjective health (Galan et al. 2010), although among adults, including the middle-aged, light or moderate intensity LTPA may have a stronger relationship with mental well-being than vigorous LTPA (Holstila et al. 2017; Panza et al. 2017). Additionally, the associations of LTPA with mental well-being and subjective health may vary: a study among Australian national park visitors showed that while walkers, hikers and runners in all age groups (age 18+) reported that visiting a national park increased their mental well-being and subjective health, the increase in mental well-being was greater than the increase in subjective health for the walkers and hikers (Wolf and Wohlfart 2014). However, different types of LTPA and different dimensions of mental well-being or subjective health have rarely been studied within the same study; hence, more information on this topic is needed.

There is also evidence that the associations between LTPA and well-being vary by gender: for example, in the above-cited study among Australian national park visitors, women experienced greater improvements in well-being than men during their park visit (Wolf and Wohlfart 2014). In addition, mild LTPA, such as walking, was related to better well-being in women aged 25-64 years whereas more intensive LTPA showed the same association in same-age men (Asztalos et al. 2010). Men and women also differ in their LTPA behavior; in Finland, for example, the physical activity guidelines for aerobic activity were met more often by women while the strength training guidelines were met more often by men (Bennie et al. 2017). It is, therefore, important not to neglect possible gender differences when studying the associations between different types of LTPA and well-being. Moreover, gender differences in the associations of different types of LTPA with well-being have not previously been studied among middle-aged people.

Despite the consistent evidence of a relationship between LTPA and well-being, the longitudinal associations remain unclear (Wiese et al. 2018). Intervention studies have shown physical exercise to be an effective way to increase well-being (Mikkelsen et al. 2017), whereas observational longitudinal studies have shown inconsistent results. For example, Xu et al. (2010) found that a higher level of LTPA was related to better current mental well-being only and did not predict mental well-being five years later among 
Australian middle-aged and older women, whereas Blomstrand et al. 2009found that a higher level of LTPA predicted better mental well-being up to 24 years later among Swedish middle-aged women. In contrast, Lahti et al. (2016), in their five- to seven-year follow-up study, found a link between a higher level of LTPA at baseline and both better mental wellbeing and better health at follow-up, although in this Finnish middle-aged sample the longitudinal association of LTPA with mental well-being was seen only among women. The focus in these studies has usually been the path from LTPA to mental well-being to the relative neglect of the possible reverse causality from mental well-being to LTPA. As an exception, Steinmo et al. (2014) in their ten-year follow-up study of middle-aged men and women revealed bidirectional longitudinal associations between LTPA and mental wellbeing. However, while participation in LTPA has generally been shown to predict better subjective health (Holstila et al. 2017; Sargent-Cox et al. 2014), the reverse, i.e., that subjective health predicts participation in LTPA, has also been reported (Weiss et al. 2007).

In middle adulthood, the time available for leisure is often severely limited by the demands of other life domains, such as work and family (Lachman 2004). In fact, among working mothers, higher dissatisfaction with time resources has been found to be related to higher goal conflict between physically active and physically passive leisure; this, in turn, is related to lower mental well-being (Williams et al. 2014). Because of these time demands, LTPA and other leisure activities are important, especially in midlife, as they are related to better recovery experiences and job performance (de Bloom et al. 2018; Sonnentag 2003). Participation in LTPA also buffers against the negative association often found between work-family spillover and subjective health (Lee et al. 2015). In addition to positive current physical and mental benefits (Garber et al. 2011; Wiese et al. 2018), participation in LTPA in midlife holds many benefits for health in older age, such as lower risk for dementia (Rovio et al. 2005), metabolic syndrome (Holme et al. 2007) and mobility limitations (Hinrichs et al. 2014; Patel et al. 2006). However, this age group has been largely neglected in well-being research (Lachman et al. 2015).

\section{Aims of the Study}

The purpose of this study was to investigate:

1) the cross-sectional associations between different types of LTPA, dimensions of mental well-being and subjective health at age 50;

2) whether, in cross-lagged longitudinal models, LTPA predicts mental well-being and subjective health, after controlling for stability in these variables from age 42 to 50, or whether, vice versa, mental well-being and subjective health predict LTPA; and

3) whether gender plays a role in these cross-sectional and longitudinal associations.

Based on the literature, we hypothesized:

(H1) that different types of LTPA are positively related to different dimensions of well-being: for example, more intensive activities (e.g. endurance and gym training) are related to subjective health, and less intensive activities (e.g. walking) and social activities (e.g. ball games) to emotional well-being;

(H2) that in the cross-lagged models, where the stability of variables is controlled for, LTPA at age 42 predicts mental well-being and subjective health at age 50; and 
(H3) that the associations differ by gender, i.e., that the types of LTPA related to mental well-being differ between women and men

\section{Method}

\section{Participants}

The data for this study were drawn from the Jyväskylä Longitudinal Study of Personality and Social Development (JYLS) (Pulkkinen 2017). The study started in 1968 with a sample of 12 randomly selected school classes of second-graders (173 girls, 196 boys $N=369$ ). Most (93.5\%) of the participants were born in 1959 and the remainder in 1958 or 1960, and thus were around eight years old at study outset (Pulkkinen 2017). Since then, the participants have been followed up to age 50 at six- to eight-year intervals.

This study used the data collected in 2001 and 2009 when the participants were 42 and 50 years old, respectively. Information was collected by life situation questionnaires, personal interviews and health examinations. The ethical committee of the Central Finland Health Care District approved the data collection in 2001 and again in 2009. Of the initial sample $(\mathrm{N}=369), 77 \%(n=285)$ at age 42 and $73 \%(n=271)$ at age 50 participated in at least one data collection method (Pulkkinen 2017). The present analyses were restricted to those who had participated in one or both data collection phases $(n=303)$. Of these, $84 \%(n=253)$ had participated in both phases. Sample sizes for the variables used in this study ranged between 217 and 284. Participants in the adult data collections were representative both of the initial sample and of their respective Finnish age cohort (Metsäpelto et al. 2010; Pulkkinen 2006).

\section{Measurements}

Leisure time physical activity (LTPA) was measured by a single question at age 42 . The same question was also used at age 50 but with supplementaries seeking more detailed information. The question asked at both ages was used in the longitudinal analyses (study question 2): "How often do you take exercise (including incidental exercise) or engage in sports in your leisure time?" The 6-point response scale was $0=$ never, $1=$ less than once a month, 2 = 1-2 times/month, 3 = once a week, 4 = 2-3 times/week, 5 = 4-5 times/week, $6=$ practically every day. At age 50, participants were also asked about their frequency of participation in 17 different types of LTPA. The 4-point response scale was $1=$ not at all or very seldom, 2 = less frequently than once a month, $3=$ once a month to four times a month and $4=$ twice a week or more frequently. Activities (e.g. skating and athletics) reported by only a few individuals (fewer than $15 \%$ at least once a month) were excluded from this study. The remaining activities were categorized into: 1) walking, including walking 3-4 kms at a time, walking $5 \mathrm{kms}$ or more at a time and Nordic walking, 2) endurance training, including running, skiing, swimming and biking, 3) group and team sports, including ball games and group fitness, 4) gym training (a single question, recoded as $0=$ less than once a month, $1=$ at least once a month) and 5) rambling in nature (a single question, recoded as $0=$ less than once a month, $1=$ at least once a month). These five categories were used in the cross-sectional analyses (study question 1) and assumed to capture both aerobic training (walking and endurance training) and strength training 
(gym training) according to general physical activity guidelines (Garber et al. 2011) as well as the benefits of spending time in a natural environment (rambling in nature) and social interaction (group and team sports). For categories 1-3, mean values were calculated. As it was not assumed that activities in the same category would necessarily correlate with each other, e.g., a participant might participate only in running but not in any type of other endurance training, Cronbach's alphas were not calculated. The total number of responses to the LTPA questions varied between 214 and 277.

Mental well-being was measured by three dimensions: emotional, psychological and social (Kokko et al. 2015). Emotional well-being included questions about life satisfaction, happiness, positive mood and negative mood (Kokko et al. 2013a, 2015). Participants were asked to rate their satisfaction in seven different domains of life (leisure, housing, financial situation, choice of occupation, present occupational situation, present intimate relationship or lack of one and present friendly relations) on a 4-point response scale from $1=$ very unsatisfied to $4=$ very satisfied (Kokko et al. 2013b). The mean value was calculated and taken to represent overall life satisfaction. Cronbach's alphas were 0.65 and 0.63 at ages 42 and 50, respectively (Kokko et al. 2013b). Deleting any items would not have improved the alpha values. Happiness was self-rated with the question "How happy or satisfied have you been at different stages of your life?" (Perho and Korhonen 1993) on a 7-point response scale from $-3=$ very unhappy or dissatisfied to $3=$ very happy or satisfied. The question referred to the age span from 40 to 42 years at age 42 and to current age at 50. Positive mood was self-rated in the interviews with two items ("Happy" and "Satisfied") and negative mood with five items (e.g. "Frightened"; (Kokkonen 2001) from the Brief Mood Introspection Scale (Feldman 1995; Mayer and Gaschke 1988) on a 4-point response scale ranging from $1=$ describes my mood not at all to $4=$ describes my mood very well. Cronbach's alphas for positive and negative mood were 0.84 and 0.68, respectively, at age 42 (Kokko et al. 2013a), and 0.79 and 0.64 at age 50 . The response scale for the negative mood items was reversed for further analyses. The emotional well-being indicators were standardized and their mean values calculated. Cronbach's alphas for emotional well-being were 0.69 at age 42 and 0.75 at age 50. Psychological well-being at ages 42 and 50 was measured with the 18item shortened form of the Scales of Psychological Well-being (Ryff 1989), where each of the components of psychological well-being (self-acceptance, positive relationships with others, environmental mastery, autonomy, purpose in life and personal growth) was measured with three items self-rated on a 4-point scale from $1=$ strongly disagree to $4=$ strongly agree. The mean score of the 18 items was computed. Cronbach's alpha was 0.75 at age 42 and 0.77 at age 50 (Kokko et al. 2013b). Social well-being was measured with the 15-item Scales of Social Well-Being (Keyes 1998). Each component of social well-being (integration, acceptance, actualization, coherence and contribution) contains three items self-rated on a 4-point scale from $1=$ strongly disagree to $4=$ strongly agree. The mean score of the 15 items was calculated. Cronbach's alpha was 0.77 at age 42 and 0.79 at age 50 (Kokko et al. 2015). The mean values of emotional, psychological and social well-being were used as indicators of the latent variable of mental well-being. Because life satisfaction was rated in life situation questionnaires and mood, happiness and psychological and social well-being in interviews, the sample sizes for these indicators at each of the two ages differed. Information on at least some of the mental well-being indicators was available for 284 and 269 participants at ages 42 and 50, respectively. 
Subjective health was measured at ages 42 and 50 by self-rated health and symptoms (Kinnunen et al. 2005). Self-rated health was asked with the question "What has your state of health been like during the past year?" on a 5-point scale from $1=$ excellent to $5=$ extremely poor. Because at both ages $1 \%$ or fewer of the participants evaluated their health as extremely poor $(=5)$, this category was merged with the adjacent one ( 4 = fairly poor). The scale was reversed, with higher values representing better selfrated health. Symptoms were measured with 19 psychological and physical symptoms (e.g., headache, stomachache, tiredness and weakness, loss of appetite, and muscular pain) drawn from the Health Symptom Checklist (Aro et al. 1987). Participants were asked to evaluate how often they had experienced the different symptoms during the last six months on a 4-point scale from $1=$ never to $4=$ very often. Participants were asked not to include symptoms regularly associated with menstruation, pregnancy or hangover. Cronbach's alphas for the scale were 0.83 at age 42 (Kinnunen et al. 2008) and 0.80 at age 50 . For the structural equation modeling, the scale was reversed, with higher values representing a lower frequency of symptoms. Self-rated health and the reverse mean value of symptoms were used as indicators of the latent variable of subjective health (Kinnunen et al. 2005). Information on at least one subjective health indicator was available for 284 participants at age 42 and 267 at age 50.

\section{Data Analysis}

Statistical analyses were performed using IBM SPSS Statistics 24.0 for descriptive statistics and to answer research question 1 and Mplus statistical package version 7.4 (Muthén and Muthén 2017) for structural equation modeling (SEM) (research question 2). For descriptive purposes, cross-sectional and longitudinal correlations between the study variables were analyzed using the Pearson correlation test. Differences in the levels of the variables at ages 42 and 50 were analyzed using the t-test for paired samples and effect sizes for mean-level changes were calculated by dividing the mean difference by the standard deviation. Differences between different groups at the same age were analyzed using ANOVA. Cross-sectional associations between the different types of LTPA, mental well-being and subjective health were analyzed by linear regression. The moderator effect of gender on mental well-being and subjective health was tested by including an interaction terms calculated between the variables for gender and activities. All regression analyses were adjusted by education and marital status.

For the SEM, the full information maximum likelihood estimation method with robust standard error and scale-corrected chi-square value (MLR estimator) with covariance matrices in Mplus was used. As the research interest was not in the mutual links between mental well-being and subjective health, they were tested in separate models. The longitudinal SEM was started by testing the measurement invariance of the latent variables in the models for the two indicators. In addition, measurement invariance for gender was analyzed with multigroup modeling. The longitudinal models included longitudinal paths a) testing stability over time in LTPA and mental well-being/subjective health (autoregressive paths), b) from LTPA to mental well-being/subjective health, and c) from mental well-being/subjective health to LTPA. LTPA and mental 
well-being/subjective health at the same measurement points were allowed to correlate. Multigroup modeling was used to test whether these paths differed between men and women.

Model fit was evaluated by the chi-square test, comparative fit index (CFI), root mean square error of approximation (RMSEA) and standardized root mean square residual (SRMR). Statistically insignificant $(p>.05)$ chi-square test values indicate an acceptable model; CFI values $>.95$ indicate acceptable fit and values $>.97$ good fit; RMSEA values between 0.05 and 0.08 indicate adequate fit and values $<.05$ good fit; and SRMR values $\leq .08$ indicate acceptable fit (Hooper et al. 2008; Schermelleh-Engel et al. 2003; Schreiber et al. 2006).

\section{Results}

\section{Descriptive Statistics}

Means and standard deviations along with bi-variate correlations between the study variables are presented in Table 1 . The correlations between all the study variables for men and women separately are available in Online Supplement 1 . The means and standard deviations for subjective health (Kinnunen et al. 2005; Kinnunen et al. 2008), mental well-being indicators at age 42 (Kokko et al. 2013a) and psychological well-being at age 50 (Kokko et al. 2013b) have been presented earlier. Happiness $(\mathrm{t}(\mathrm{df})=-3.19(202), p=.002$; effect size $(\mathrm{d})=.22)$ and social well-being $(\mathrm{t}(\mathrm{df})=-6.12(199), p<.001 ; \mathrm{d}=.43)$ tended to increase over time from age 42 to age 50, as reported earlier (Kokko 2010). The mean level of LTPA also increased from age 42 to age $50(\mathrm{t}(\mathrm{df})=-3.93(241), p<.001$; $\mathrm{d}=.25$ ).

At age 42, LTPA was not associated with any well-being indicator. At age 50 , however, it correlated with the subjective health indicators and with psychological well-being and positive mood. All the different types of LTPA correlated positively with some well-being indicators at age 50, with the exception of group and team sports, which showed no associations with the well-being indicators.

\section{Cross-Sectional Associations between LTPA, Mental Well-Being and Subjective Health}

Cross-sectional associations between leisure time physical activities and wellbeing at age 50 were analyzed by linear regression (Table 2). A separate model for each well-being indicator was conducted. The moderator effect of gender was investigated in regression models that included the main variables (gender and activity) and the interaction term between them. Statistically significant interaction terms were included in the final models containing all activities. All regression analyses were adjusted by education and marital status.

Rambling in nature showed interaction effects between gender and emotional well-being and subjective health (Table 2). All the other interaction terms were statistically insignificant $(\mathrm{p}>.05)$. The interaction effects of rambling in nature 
Table 1 Descriptive statistics and bi-variate correlations between the study variables

\begin{tabular}{|c|c|c|c|c|c|c|c|c|c|c|}
\hline \multirow[b]{2}{*}{ Variables } & \multirow[b]{2}{*}{ M } & \multirow[b]{2}{*}{$\mathrm{SD}$} & \multirow[b]{2}{*}{ ES } & \multirow{2}{*}{$\begin{array}{l}\text { Age } \\
42 \\
\text { LTPA }\end{array}$} & \multicolumn{6}{|l|}{ Age 50} \\
\hline & & & & & LTPA & Walking & ET & GTS & GT & RIN \\
\hline \multicolumn{11}{|l|}{ Age 42} \\
\hline Life satisfaction & 3.08 & .43 & & .02 & .10 & $.14^{*}$ & -.02 & -.08 & .08 & $.15^{*}$ \\
\hline Positive mood & 2.82 & .67 & & -.02 & .05 & .11 & -.05 & -.04 & .06 & .14 \\
\hline Negative mood ${ }^{\mathrm{a}}$ & 3.81 & .30 & & -.07 & $.18 * *$ & .11 & -.04 & .03 & .03 & .09 \\
\hline Happiness & 1.64 & 1.32 & & .10 & .13 & .08 & -.05 & -.09 & -.05 & .03 \\
\hline $\begin{array}{l}\text { Psychological } \\
\text { well-being }\end{array}$ & 3.14 & .34 & & .08 & $.16^{*}$ & .12 & -.02 & .04 & .08 & .08 \\
\hline Social well-being & 2.82 & .38 & & -.00 & $.14^{*}$ & $.15^{*}$ & -.01 & -.02 & .05 & $.14^{*}$ \\
\hline Self-rated health & 2.81 & .77 & & .05 & .08 & .08 & $.14 *$ & .09 & .06 & -.02 \\
\hline $\begin{array}{l}\text { Psychosomatic } \\
\text { symptoms }^{\mathrm{a}}\end{array}$ & 2.45 & .33 & & -03 & -.10 & .01 & .09 & .02 & .08 & -.03 \\
\hline LTPA & 3.86 & 1.51 & & & $.41 * * *$ & $.16^{*}$ & $.22 * *$ & .11 & $.21 * *$ & $.15^{*}$ \\
\hline \multicolumn{11}{|l|}{ Age 50} \\
\hline Life satisfaction & 3.08 & .44 & -.02 & .03 & .06 & .07 & .07 & .06 & .07 & $.14 *$ \\
\hline Positive mood & 2.91 & .61 & .12 & -.02 & $.13^{*}$ & .08 & .10 & .11 & .12 & .08 \\
\hline Negative mood ${ }^{a}$ & 3.81 & .32 & .00 & -.07 & .07 & .01 & .04 & .03 & .06 & .05 \\
\hline Happiness & 1.89 & .99 & $.22^{\mathrm{b}}$ & .04 & .11 & $.21 * *$ & .12 & .05 & .10 & $.17 *$ \\
\hline $\begin{array}{l}\text { Psychological } \\
\text { well-being }\end{array}$ & 3.18 & .33 & .14 & .01 & $.14^{*}$ & $.19 * *$ & .03 & -.03 & -.01 & .12 \\
\hline Social well-being & 2.96 & .39 & $.43^{b}$ & .11 & .03 & $.16^{*}$ & .01 & -.02 & .02 & $.24 * * *$ \\
\hline Self-rated health & 2.78 & .84 & -.09 & .06 & $.21 * *$ & $.15^{*}$ & $.20 * *$ & .11 & $.15^{*}$ & .06 \\
\hline $\begin{array}{l}\text { Psychosomatic } \\
\text { symptoms }^{\mathrm{a}}\end{array}$ & 2.41 & .34 & -.12 & -.04 & $-.18 * *$ & -.06 & $-.21 * *$ & -.12 & $-.15^{*}$ & .05 \\
\hline LTPA & $4.20^{\mathrm{a}}$ & 1.55 & $.25^{\mathrm{b}}$ & $.41 * * *$ & & $.28 * * *$ & $.20 * *$ & $.20 * *$ & $.26^{* * *}$ & .01 \\
\hline Walking & 2.89 & .90 & & & & & & & & \\
\hline Endurance training & 2.02 & .60 & & & & & & & & \\
\hline Group \& team sports & 1.53 & .68 & & & & & & & & \\
\hline \multicolumn{11}{|l|}{ Gym training ${ }^{c}$} \\
\hline$<1 \mathrm{x} /$ month & $69.6 \%$ & & & & & & & & & \\
\hline$\geq 1 \mathrm{x} /$ month & $30.4 \%$ & & & & & & & & & \\
\hline \multicolumn{11}{|l|}{ Rambling in nature ${ }^{b}$} \\
\hline$<1 \mathrm{x} /$ month & $56.3 \%$ & & & & & & & & & \\
\hline$\geq 1 \mathrm{x} /$ month & $43.7 \%$ & & & & & & & & & \\
\hline
\end{tabular}

ES effect size, LTPA Leisure time physical activity, ET endurance training, GTS group and team sports, GT gym training, RIN rambling in nature

${ }^{a}$ Reversed scale,

${ }^{\mathrm{b}}$ paired sample t-test $p<.05$ between times

${ }^{\mathrm{c}}$ Frequencies presented, correlations $* p<.05, * * p<.01$, *** $p<.001$ 
Table 2 Linear regression analysis of types of leisure time physical activity on the dimensions of well-being at age 50

\begin{tabular}{|c|c|c|c|c|c|c|c|c|}
\hline & \multicolumn{2}{|c|}{$\begin{array}{l}\text { Emotional well- } \\
\text { being }\end{array}$} & \multicolumn{2}{|c|}{$\begin{array}{l}\text { Psychological well- } \\
\text { being }\end{array}$} & \multicolumn{2}{|c|}{$\begin{array}{l}\text { Social well- } \\
\text { being }\end{array}$} & \multicolumn{2}{|c|}{$\begin{array}{l}\text { Subjective } \\
\text { health }\end{array}$} \\
\hline & $\beta$ & $\mathrm{p}$ & $\beta$ & $\mathrm{p}$ & $\beta$ & $\mathrm{p}$ & $\beta$ & $\mathrm{p}$ \\
\hline Walking & .14 & .202 & .35 & .001 & .10 & .336 & .08 & .437 \\
\hline Endurance training & .18 & .129 & .01 & .908 & -.04 & .704 & .32 & .007 \\
\hline Group\&team sports & .18 & .141 & -.11 & .360 & -.02 & .847 & .06 & .594 \\
\hline Gym training & .01 & .896 & -.07 & .493 & -.07 & .477 & .07 & .515 \\
\hline Rambling in nature & -.15 & .153 & .14 & .183 & .24 & .025 & -.17 & .118 \\
\hline Gender & -1.21 & .006 & -.29 & .494 & .32 & .451 & -.51 & .240 \\
\hline Gender * walking & -.20 & .560 & -.57 & .088 & .25 & .455 & .13 & .697 \\
\hline Gender * endurance training & -.46 & .153 & -.07 & .830 & -.10 & .757 & -.52 & .109 \\
\hline Gender * group\&team sports & -.44 & .100 & .16 & .546 & .09 & .745 & -.08 & .754 \\
\hline Gender*gym training & .07 & .560 & .09 & .426 & .09 & .433 & -.04 & .710 \\
\hline Gender * rambling in nature & .35 & .005 & -.17 & .162 & -.08 & .516 & .25 & .042 \\
\hline Model p & .002 & & $<.001$ & & .001 & & .002 & \\
\hline Model Adj. $\mathrm{R}^{2}$ & .09 & & .14 & & .11 & & .10 & \\
\hline
\end{tabular}

Models adjusted by educational level and marital status

between gender and and emotional well-being and subjective health are shown in Fig. 1: participation in rambling in nature was associated with better emotional well-being and subjective health only among men. In both genders, positive associations were found between walking and psychological well-being, rambling in nature and social well-being, and endurance training and subjective health.

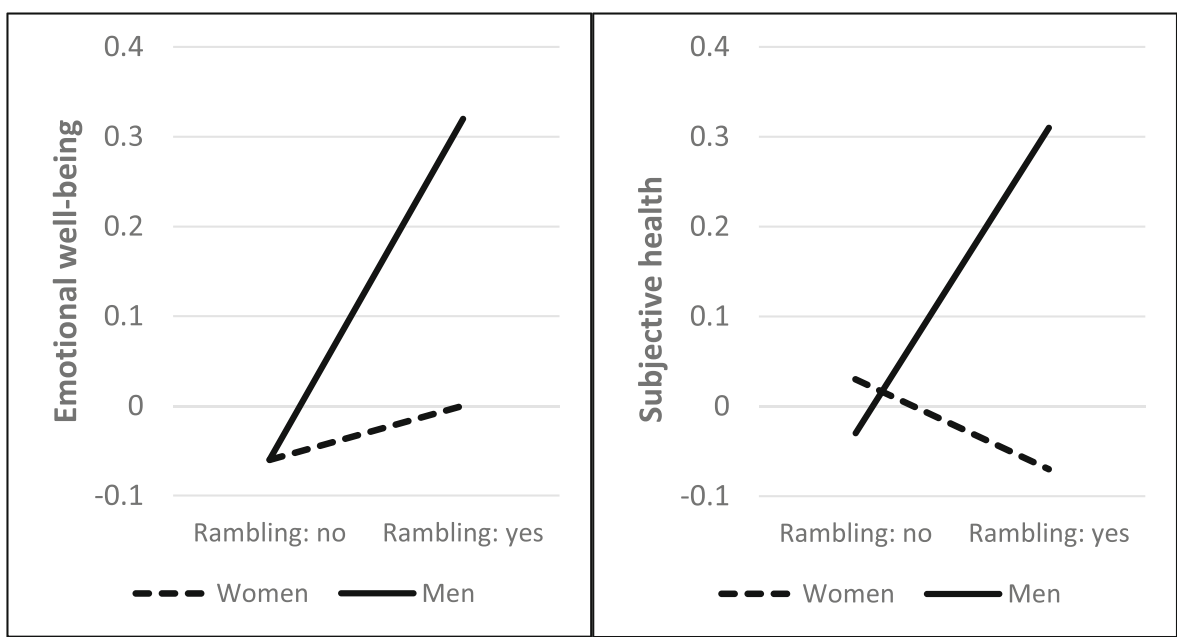

Fig. 1 Interaction effect of participation in rambling in nature and gender on emotional well-being and subjective health 


\section{Longitudinal Associations between LTPA and Mental Well-Being and Subjective Health}

The first models testing measurement invariance in mental well-being and subjective health between ages 42 and 50 revealed that some of the error terms of the corresponding indicators of the latent variables had to be allowed to correlate to obtain an acceptable model fit. These error terms were emotional and social well-being between both ages in the mental well-being models, and self-rated health at both ages in the subjective health models. The model fit indices for the first mental well-being model were $\mathrm{x}^{2}=81.714$ ( $\mathrm{df}$ $16), p<.001 ; \mathrm{CFI}=.846$; RMSEA $=.194$ and for the model with correlated error terms $\mathrm{x}^{2}=6.724(\mathrm{df} 3), p=.081 ; \mathrm{CFI}=.992 ; \mathrm{RMSEA}=.061$. The model fit indices for the corresponding subjective health models were $\mathrm{x}^{2}=48.878$ (df 7), $\mathrm{p}<.001$; CFI = .916; RMSEA $=.135$ and $x^{2}=5.557(\mathrm{df} 4), p=.235 ; \mathrm{CFI}=.997$; RMSEA $=.035$.

In the mental well-being SEM models, constraining the factor loadings (difference test $\mathrm{x} 2=0.94(\mathrm{df}=2), p=.624)$ and error variances (difference test $\mathrm{x}^{2}=3.02(\mathrm{df}=3)$, $p=.389$ ) to be equal between ages 42 and 50 did not lead to a significant reduction in model fit. In addition, multigroup testing showed that the same measurement model was suitable for both genders (difference test $\left.\mathrm{x}^{2}=12.10(\mathrm{df}=6), p=.060\right)$. In the subjective health SEM models, the factor loadings (difference test $\mathrm{x}^{2}=.004(\mathrm{df}=1)$, $p=.950)$, error variances (difference test $\left.\mathrm{x}^{2}=5.783(\mathrm{df}=2), p=.056\right)$ and intercepts (difference test $\left.\mathrm{x}^{2}=4.72(\mathrm{df}=2), p=.095\right)$ were constrained to be equal between time points. The multigroup analysis indicated no gender differences in the measurement model (difference test $\left.\mathrm{x}^{2}=8.20(\mathrm{df}=4), p=.085\right)$.

The longitudinal models are presented in Figs. 2 and 3. Both models showed adequate fit: for mental well-being $\mathrm{x}^{2}=28.949$ (df 19), $p=.067$; CFI = .984; RMSEA $=.042$, and for subjective health $\mathrm{x}^{2}=11.190$ (df 9), $p=.263$; CFI =.993; RMSEA $=.028$. Mental well-being and subjective health showed high stability over time $(\beta=.85, p<.001$ for mental well-being and $\beta=.77, p<.001$ for subjective health). Mental well-being (including the absence of depressive symptoms) has previously shown high stability (Kokko et al. 2015). In addition, LTPA was significantly stable $(\beta=.42, \mathrm{p}<.001)$. Mental well-being at age 42 preceded LTPA at age 50, whereas subjective health and LTPA showed no longitudinal associations. The multi-

AGE 42

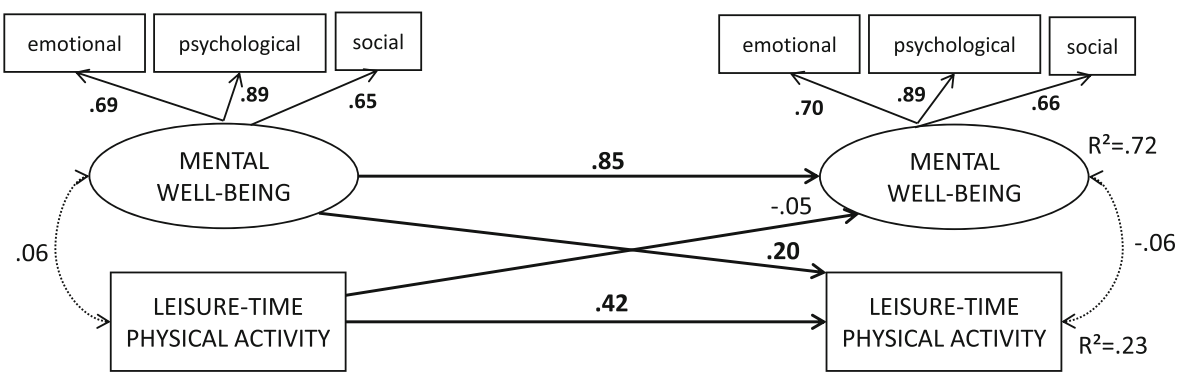

Fig. 2 Longitudinal associations between leisure time physical activity and mental well-being. Structural equation model with standardized regression coefficients. Statistically significant $(\mathrm{p}<.05)$ coefficients bolded. For ease of reading. Error terms are not shown. Model fit: $\mathrm{x}^{2}=28.949$ (df 19). $\mathrm{p}=.067$; CFI = .984; RMSEA $[90 \% \mathrm{CI}]=0.042[0.000 .0 .071] . \mathrm{SRMR}=0.044$ 
AGE 42

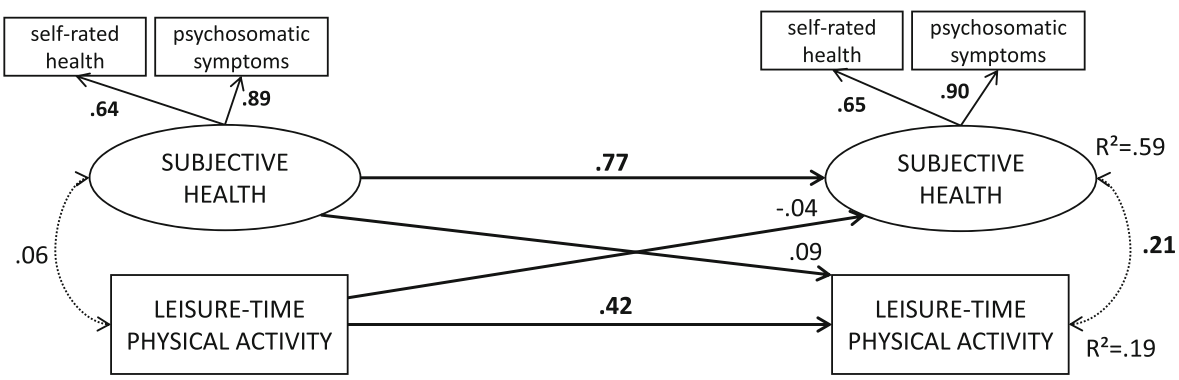

Fig. 3 Longitudinal associations between leisure time physical activity and subjective health. Structural equation model with standardized regression coefficients. Statistically significant $(\mathrm{p}<.05)$ coefficients bolded. For ease of reading. Error terms are not shown. Model fit: $x^{2}=11.190$ (df 9). $p=.263$; CFI =.993; RMSEA $[90 \% \mathrm{CI}]=0.028[0.000 .0 .074] . \mathrm{SRMR}=0.065$

group analysis indicated equal paths between men and women (for mental well-being difference test $\mathrm{x}^{2}=12.104(\mathrm{df}=6), \mathrm{p}=.060$; and for subjective health difference test $\left.\mathrm{x}^{2}=5.663(\mathrm{df}=6), p=.460\right)$. Therefore, the results are presented for the whole sample (Figs. 2 and 3 ).

\section{Discussion}

This study investigated the cross-sectional and longitudinal associations between LTPA, mental well-being and subjective health in middle-aged adults. As expected (H1), the cross-sectional analyses revealed that different types of LTPA were positively associated with subjective health and different dimensions of mental well-being. Interestingly, the direction of the longitudinal cross-lagged associations was not, as hypothesized $(\mathrm{H} 2)$, from LTPA to mental well-being or subjective health. Instead, mental well-being at age 42 predicted LTPA at age 50. Moreover, LTPA and subjective health showed no longitudinal associations. The results also found an unexpected difference between men and women: participation in rambling was related to better emotional well-being and subjective health only among men. Thus, hypothesis 3 (H3) was partly supported.

While a positive association between LTPA and mental well-being has been widely reported (Brown et al. 2000; Holstila et al. 2017; Lahti et al. 2016; Penedo and Dahn 2005; Södergren et al. 2008; Wiese et al. 2018), the associations between different types of LTPA and different dimensions of mental well-being, and possible gender differences in these, have not previously been investigated in the same study. As previously mentioned, rambling in nature contributed to emotional well-being and subjective health only among men. Rambling in nature may mean different things to men and women: men may prefer more intensive outdoor activities. For example, rambling in nature correlated positively with the frequency of exercise duration of at least half an hour, being out of breath and sweating among men, but not among women. This is in line with previous finding that greater stress release was observed among the park and forest visitors who practiced sports compared to less strenuous activities such as going for a walk (Hansmann et al. 2007). 
The other associations with well-being observed in this study were similar for both genders: walking was related to better psychological well-being and rambling in nature to better social well-being. These results may reflect the importance of outdoor activities and nature for well-being, as it has been shown earlier that connectedness with nature is positively associated with emotional, psychological and social well-being (Howell et al. 2011). Moreover, endurance training was the only type of LTPA associated with subjective health in both genders. It is possible that in midlife, when most people are relatively healthy, only more intensive types of LTPA, such as running, are related to better health. These results support previous findings that light or moderate intensity LTPA is related to mental well-being (Holstila et al. 2017; Panza et al. 2017) whereas more intensive LTPA is related to better subjective health (Galan et al. 2010). In contrast to some earlier findings (Andersen et al. 2018; Doré et al. 2016; Eime et al. 2010; O'Connor et al. 2010), this study did not find any associations between team and group sports or gym training and mental well-being/subjective health. These were the least commonly reported activities among the types of LTPA studied: less than one-third of the participants engaged in them at least once a month. It seems that these types of LTPA have more importance for younger or older adults than the middle-aged ones. In sum, to enhance all dimensions of well-being in midlife, diversity in LTPA is important: benefits are gained from both more intensive and more relaxing activities.

However, the longitudinal results of this study run counter to the expectation that LTPA leads to better mental well-being and subjective health (Newman et al. 2014; Sonnentag 2003; Sonnentag and Bayer 2005). The unexpected direction of the association also conflicts with earlier longitudinal research findings on LTPA and mental well-being and subjective health (deRezende et al. 2014; Holstila et al. 2017; Lahti et al. 2016; Takeda et al. 2015). The age of the participants, namely 42 to 50, may be the main reason for these unexpected results. This interpretation is supported by previous findings of a longitudinal association between LTPA and well-being among older (65+) men and women (Ku et al. 2014; Lee and Russell 2003) but only a crosssectional association among middle-aged women (Xu et al. 2010). Some evidence exists that LTPA is related to lower perceived stress levels among retired older adults but not among middle-aged employed adults (Zuzanek et al. 1998). Middle adulthood is typically the busiest time in people's lives, as it includes meeting responsibilities towards one's children and one's parents as well as high job demands, and thus leaves little free time for leisure activities (Knecht et al. 2016; Lachman et al. 2015). It is possible that the present middle-aged participants also had only a small amount of leisure time and therefore other factors in their life were more important for their wellbeing. In addition, the eight-year interval between measurements leaves a lot of time for the possible occurrence of major life changes.

One potential mechanism behind the longitudinal association between mental wellbeing and LTPA is personality, which is closely related not only to mental well-being (Kokko et al. 2015; Steel et al. 2008) but also to LTPA (Rhodes and Smith 2006). For example, the personality traits of playfulness (Proyer et al. 2018) and activity (facet of extraversion) (Rhodes et al. 2002; Røysamb et al. 2018) are linked to both mental wellbeing and LTPA. Like mental well-being (Kokko et al. 2013a), personality has high rank-order stability in adulthood (Rantanen et al. 2007; Roberts and DelVecchio 2000); this might explain why LTPA did not predict mental well-being in this study but vice 
versa. In future studies, it would be interesting to study the potential mechanisms behind both the cross-sectional and longitudinal associations of LTPA with well-being.

In any case, it is clear that participation in LTPA in midlife has many benefits for both current and later health and functional capacity (Patel et al. 2006; Rovio et al. 2005), and hence it is important to find ways to promote participation in LTPA in midlife. Longitudinal investigation of the profiles of mental well-being conducted within the JYLS has shown that, in general, people with at least relatively good mental well-being function well in other areas of life such as work and social relations (Kokko and Feldt 2018). In addition, Rebar and Taylor (2017) have suggested that special attention should be paid to people with mental health issues, as the facilitators and barriers to participation in LTPA perceived by these individuals might diverge from those of the average population. It is possible that in midlife well-being is an important resource for promoting participation in LTPA, and therefore, individuals with low wellbeing should be especially targeted in campaigns to improved participation in LTPA.

\section{Limitations}

This study has its limitations. First, as this was a secondary analysis of a larger dataset, some of the measurements used were not optimal. The Cronbach's alphas for overall life satisfaction (including satisfaction in seven life domains) were lower than 0.70 , indicating somewhat low internal consistency. However, as overall life satisfaction was used together with three other measurements (happiness, positive mood and negative mood) to evaluate emotional well-being, the low alpha value should not have influenced the results. Additionally, the LTPA measurements were not optimal. LTPA at age 42 was measured with a single question; hence, especially in the longitudinal analysis, it was not possible to capture the phenomenon in its entirety. In addition to frequency of participation in LTPA, this study would have benefited from information about exercise intensity and duration. Second, having only two measurement points with comparable measures of physical activity frequency, it was not possible to use more sophisticated statistical methods, such as growth curve modelling, to analyze change. Moreover, more measurement points at shorter intervals would have produced stronger evidence on the causal relationships between the study variables.

\section{Conclusions}

This study investigated the middle stages of midlife with a representative sample of the Finnish age cohort born in 1959. The cross-sectional results showed that different types of LTPA were associated with different dimensions of well-being and the longitudinal results that mental well-being predicted LTPA. To gain a more complete picture of the associations of age and life-stage differences with LTPA and subjective experiences of mental well-being and health, further studies that take the multidimensionality of both well-being and LTPA into account are called for. It is also important to find ways to promote mental well-being in midlife as this seems to be an important resource for participation in physical activity. In addition, middle-aged adults should be encouraged to find the time to participate in different types of physical activities, even if their leisure time is limited. 
Acknowledgements The authors appreciate Professor Lea Pulkkinen's contribution to the Jyväskylä Longitudinal Study of Personality and Social Development over the years. This study was presented at the Gerontological Society of America Annual Scientific Meeting in Boston, USA, November 2018.

Funding Open access funding provided by University of Jyväskylä (JYU). The most recent JYLS data collection in 2009 was funded by the Academy of Finland through grants Nos. 127125 and 118316. This work was supported by a personal grant to Tiia Kekäläinen from the Finnish Cultural Foundation.

\section{Compliance with Ethical Standards}

Informed Consent Informed consent was obtained from all individual participants included in the study.

Conflict of Interest The authors declare that they have no conflict of interest.

Open Access This article is distributed under the terms of the Creative Commons Attribution 4.0 International License (http://creativecommons.org/licenses/by/4.0/), which permits unrestricted use, distribution, and reproduction in any medium, provided you give appropriate credit to the original author(s) and the source, provide a link to the Creative Commons license, and indicate if changes were made.

\section{References}

Andersen, M. H., Ottesen, L., \& Thing, L. F. (2018). The social and psychological health outcomes of team sport participation in adults: An integrative review of research. Scandinavian Journal of Public Health. https://doi.org/10.1177/1403494818791405.

Aro, H., Paronen, O., \& Aro, S. (1987). Psychosomatic symptoms among 14-16 year old Finnish adolescents. Social Psychiatry, 22, 171-176.

Asztalos, M., De Bourdeaudhuij, I., \& Cardon, G. (2010). The relationship between physical activity and mental health varies across activity intensity levels and dimensions of mental health among women and men. Public Health Nutrition, 13(8), 1207-1214.

Asztalos, M., Wijndaele, K., De Bourdeaudhuij, I., Philippaerts, R., Matton, L., Duvigneaud, N., et al. (2012). Sport participation and stress among women and men. Psychology of Sport and Exercise, 13(4), 466-483.

Bennie, J. A., Pedisic, Z., Suni, J. H., Tokola, K., Husu, P., Biddle, S. J., \& Vasankari, T. (2017). Self-reported health-enhancing physical activity recommendation adherence among 64,380 Finnish adults. Scandinavian Journal of Medicine \& Science in Sports, 27(12), 1842-1853.

Blomstrand, A., Björkelund, C., Ariai, N., Lissner, L., \& Bengtsson, C. (2009). Effects of leisure-time physical activity on well-being among women: A 32-year perspective. Scandinavian Journal of Public Health, 37(7), 706-712.

Brown, W. J., Mishra, G., Lee, C., \& Bauman, A. (2000). Leisure time physical activity in Australian women: Relationship with well being and symptoms. Research Quarterly for Exercise and Sport, 71(3), 206-216.

Chang, P., Lin, Y., \& Song, R. (2018). Leisure satisfaction mediates the relationships between leisure settings, subjective well-being, and depression among middle-aged adults in urban China. Applied Research in Quality of Life. https://doi.org/10.1007/s11482-018-9630-3.

de Bloom, J., Rantanen, J., Tement, S., \& Kinnunen, U. (2018). Longitudinal leisure activity profiles and their associations with recovery experiences and job performance. Leisure Sciences, 40(3), 151-173.

deRezende, L. F. M., Rodrigues Lopes, M., Rey-López, J. P., Matsudo, V. K. R., \& Luiz, O. C. (2014). Sedentary behavior and health outcomes: An overview of systematic reviews. PLoS One, 9(8), e105620.

Diener, E., Suh, E. M., Lucas, R. E., \& Smith, H. L. (1999). Subjective well-being: Three decades of progress. Psychological Bulletin, 125(2), 276-302.

Doré, I., O'Loughlin, J. L., Beauchamp, G., Martineau, M., \& Fournier, L. (2016). Volume and social context of physical activity in association with mental health, anxiety and depression among youth. Preventive Medicine, 91, 344-350.

Eime, R. M., Harvey, J. T., Brown, W. J., \& Payne, W. R. (2010). Does sports club participation contribute to health-related quality of life? Medicine and Science in Sports and Exercise, 42(5), 1022-1028. 
Feldman, L. A. (1995). Valence arousal and arousal focus: Individual differences in the structure of affective experience. Journal of Personality and Social Psychology, 69(1), 153-166.

Galan, I., Meseguer, C. M., Herruzo, R., \& Rodriguez-Artalejo, F. (2010). Self-rated health according to amount, intensity and duration of leisure time physical activity. Preventive Medicine, 51(5), 378-383.

Garber, C. E., Blissmer, B., Deschenes, M. R., Franklin, B. A., Lamonte, M. J., Lee, I. M., et al. (2011). American College of Sports Medicine position stand. Quantity and quality of exercise for developing and maintaining cardiorespiratory, musculoskeletal, and neuromotor fitness in apparently healthy adults: Guidance for prescribing exercise. Medicine and Science in Sports and Exercise, 43(7), 1334-1359.

Hamer, M., Stamatakis, E., \& Mishra, G. D. (2010). Television- and screen-based activity and mental wellbeing in adults. American Journal of Preventive Medicine, 38(4), 375-380.

Hansmann, R., Hug, S., \& Seeland, K. (2007). Restoration and stress relief through physical activities in forests and parks. Urban Forestry \& Urban Greening, 6(4), 213-225.

Hinrichs, T., Bonsdorff, M. B., Törmäkangas, T., Bonsdorff, M. E., Kulmala, J., Seitsamo, J., et al. (2014). Inverse effects of midlife occupational and leisure time physical activity on mobility limitation in old age-A 28-year prospective follow-up study. Journal of the American Geriatrics Society, 62(5), 812-820.

Holme, I., Tonstad, S., Sogaard, A. J., Larsen, P. G. L., \& Haheim, L. L. (2007). Leisure time physical activity in middle age predicts the metabolic syndrome in old age: Results of a 28-year follow-up of men in the Oslo study. BMC Public Health, 7(1), 154.

Holstila, A., Mänty, M., Rahkonen, O., Lahelma, E., \& Lahti, J. (2017). Changes in leisure-time physical activity and physical and mental health functioning: A follow-up study. Scandinavian Journal of Medicine \& Science in Sports, 27, 1785-1792.

Hooper, D., Coughlan, J., \& Mullen, M. R. (2008). Structural equation modelling: Guidelines for determining model fit. The Electronic Journal of Business Research Methods, 6(1), 53-60.

Howell, A. J., Dopko, R. L., Passmore, H., \& Buro, K. (2011). Nature connectedness: Associations with wellbeing and mindfulness. Personality and Individual Differences, 51(2), 166-171.

Keyes, C. L. (1998). Social well-being. Social Psychology Quarterly, 61, 121-140.

Keyes, C. L. (2005). Mental illness and/or mental health? Investigating axioms of the complete state model of health. Journal of Consulting and Clinical Psychology, 73(3), 539-548.

Kinnunen, M., Kokkonen, M., Kaprio, J., \& Pulkkinen, L. (2005). The associations of emotion regulation and dysregulation with the metabolic syndrome factor. Journal of Psychosomatic Research, 58(6), 513-521.

Kinnunen, M., Feldt, T., Kinnunen, U., \& Pulkkinen, L. (2008). Self-esteem: An antecedent or a consequence of social support and psychosomatic symptoms? Cross-lagged associations in adulthood. Journal of Research in Personality, 42(2), 333-347.

Knecht, M., Wiese, B. S., \& Freund, A. M. (2016). Going beyond work and family: A longitudinal study on the role of leisure in the work-life interplay. Journal of Organizational Behavior, 37(7), 1061-1077.

Kokko, K. (2010). Psyykkinen hyvinvointi. In L. Pulkkinen \& K. Kokko (Eds.), Keski-ikä elämänvaiheena [Middle age as a stage of life] (pp. 91-96). University of Jyväskylä: Department of Psychology.

Kokko, K., \& Feldt, T. (2018). Longitudinal profiles of mental well-being as correlates of successful aging in middle age. International Journal of Behavioral Development, 42(5), 485-495.

Kokko, K., Korkalainen, A., Lyyra, A., \& Feldt, T. (2013a). Structure and continuity of well-being in midadulthood: A longitudinal study. Journal of Happiness Studies, 14(1), 99-114.

Kokko, K., Tolvanen, A., \& Pulkkinen, L. (2013b). Associations between personality traits and psychological well-being across time in middle adulthood. Journal of Research in Personality, 47(6), 748-756.

Kokko, K., Rantanen, J., \& Pulkkinen, L. (2015). Associations between mental well-being and personality from a life span perspective. In M. Blatný (Ed.), Personality and well-being across the life-span (pp. 134 159). London: Palgrave.

Kokkonen, M. (2001). Emotion regulation and physical health in adulthood: a longitudinal, personalityoriented approach. Jyväskylä Studies in Education, Psychology and Social Research, No. 184. Jyväskylä: University of Jyväskylä.

Ku, P., Fox, K., Chang, C., Sun, W., \& Chen, L. (2014). Cross-sectional and longitudinal associations of categories of physical activities with dimensions of subjective well-being in Taiwanese older adults. Social Indicators Research, 117(3), 705-718.

Lachman, M. E. (2004). Development in midlife. Annual Review of Psychology, 55, 305-331.

Lachman, M. E., Teshale, S., \& Agrigoroaei, S. (2015). Midlife as a pivotal period in the life course: Balancing growth and decline at the crossroads of youth and old age. International Journal of Behavioral Development, 39(1), 20-31.

Lahti, J., Sabia, S., Singh-Manoux, A., Kivimaki, M., Tatsuse, T., Yamada, M., et al. (2016). Leisure time physical activity and subsequent physical and mental health functioning among midlife Finnish, British and Japanese employees: A follow-up study in three occupational cohorts. BMJ Open, 6(1), 009788. 
Lee, C., \& Russell, A. (2003). Effects of physical activity on emotional well-being among older Australian women: Cross-sectional and longitudinal analyses. Journal of Psychosomatic Research, 54(2), 155-160.

Lee, B., Lawson, K. M., Chang, P., Neuendorf, C., Dmitrieva, N. O., \& Almeida, D. M. (2015). Leisure-time physical activity moderates the longitudinal associations between work-family spillover and physical health. Journal of Leisure Research, 47(4), 444 466.

Mayer, J. D., \& Gaschke, Y. N. (1988). The experience and meta-experience of mood. Journal of Personality and Social Psychology, 55(1), 102-111.

McAuley, E., \& Rudolp, D. (1995). Physical activity, aging and psychological well-being. Journal of Aging and Physical Activity, 3, 67-96.

Metsäpelto, R., Polet, J., Kokko, K., Rantanen, J., Kinnunen, M., Pitkänen, T., et al. (2010). Tutkimuksen toteutus. In L. Pulkkinen \& K. Kokko (Eds.), Keski-ikä elämänvaiheena. Jyväskylän yliopiston psykologian laitoksen julkaisuja 352 (pp. 5-19). Jyväskylä: University of Jyväskylä.

Mikkelsen, K., Stojanovska, L., Polenakovic, M., Bosevski, M., \& Apostolopoulos, V. (2017). Exercise and mental health. Maturitas, 106, 48-56.

Muthén, L. K., \& Muthén, B. O. (2017). Mplus User's Guide (8th ed.). Los Angeles: Muthén \& Muthén.

Nawijn, J., \& Veenhoven, R. (2013). Happiness through leisure. In T. Freire (Ed.), Positive leisure science: From subjective experience to social contexts (pp. 193-209). Dordrecht: Springer Netherlands.

Netz, Y., Wu, M. J., Becker, B. J., \& Tenenbaum, G. (2005). Physical activity and psychological well-being in advanced age: A meta-analysis of intervention studies. Psychology and Aging, 20(2), 272-284.

Newman, D. B., Tay, L., \& Diener, E. (2014). Leisure and subjective well-being: A model of psychological mechanisms as mediating factors. Journal of Happiness Studies, 15(3), 555-578.

O'Connor, P. J., Herring, M. P., \& Caravalho, A. (2010). Mental health benefits of strength training in adults. American Journal of Lifestyle Medicine, 4(5), 377-396.

Oh, S. H., Son, S. H., Kang, S. H., Kim, D. K., Seo, K. M., \& Lee, S. Y. (2017). Relationship between types of exercise and quality of life in a Korean metabolic syndrome population: A cross-sectional study. Metabolic Syndrome and Related Disorders, 15(4), 199-205.

Panza, G. A., Taylor, B. A., Thompson, P. D., White, C. M., \& Pescatello, L. S. (2017). Physical activity intensity and subjective well-being in healthy adults. Journal of Health Psychology. https://doi. org/10.1177/1359105317691589.

Patel, K. V., Coppin, A. K., Manini, T. M., Lauretani, F., Bandinelli, S., Ferrucci, L., \& Guralnik, J. M. (2006). Midlife physical activity and mobility in older age: The InCHIANTI study. American Journal of Preventive Medicine, 31(3), 217-224.

Penedo, F. J., \& Dahn, J. R. (2005). Exercise and well-being: A review of mental and physical health benefits associated with physical activity. Current Opinion in Psychiatry, 18(2), 189-193.

Perho, H., \& Korhonen, M. (1993). Elämänvaiheiden onnellisuus ja sisältö keski-iän kynnyksellä [Happiness and content of different life phases in the frontier of midadulthood]. Gerontologia, 7, 271-285.

Pietilä, M., Neuvonen, M., Borodulin, K., Korpela, K., Sievänen, T., \& Tyrväinen, L. (2015). Relationships between exposure to urban green spaces, physical activity and self-rated health. Journal of Outdoor Recreation and Tourism, 10, 44-54.

Proyer, R. T., Gander, F., Bertenshaw, E. J., \& Brauer, K. (2018). The positive relationships of playfulness with indicators of health, activity, and physical fitness. Frontiers in Psychology, 9, 1440.

Pulkkinen, L. (2006). The Jyväskylä longitudinal study of personality and social development. In L. Pulkkinen, J. Kaprio, \& R. J. Rose (Eds.), Socioemotional development and health from adolescence to adulthood (pp. 29-55). New York: Cambridge University Pres.

Pulkkinen, L. (2017). Human development from middle childhood to middle adulthood: Growing up to the middle-aged (in collaboration with Katja Kokko). London: Routledge.

Rantanen, J., Metsapelto, R. L., Feldt, T., Pulkkinen, L., \& Kokko, K. (2007). Long-term stability in the big five personality traits in adulthood. Scandinavian Journal of Psychology, 48(6), 511-518.

Rebar, A. L., \& Taylor, A. (2017). Physical activity and mental health; it is more than just a prescription. Mental Health and Physical Activity, 13, 77-82.

Rhodes, R. E., \& Smith, N. E. I. (2006). Personality correlates of physical activity: A review and metaanalysis. British Journal of Sports Medicine, 40(12), 958-965.

Rhodes, R. E., Courneya, K. S., \& Jones, L. W. (2002). Personality, the theory of planned behavior, and exercise: A unique role for Extroversion's activity facet. Journal of Applied Social Psychology, 32(8), $1721-1736$.

Roberts, B. W., \& DelVecchio, W. F. (2000). The rank-order consistency of personality traits from childhood to old age: A quantitative review of longitudinal studies. Psychological Bulletin, 126(1), 3-25. 
Rovio, S., Kareholt, I., Helkala, E. L., Viitanen, M., Winblad, B., Tuomilehto, J., et al. (2005). Leisure-time physical activity at midlife and the risk of dementia and Alzheimer's disease. The Lancet Neurology, 4(11), 705-711.

Røysamb, E., Nes, R. B., Czajkowski, N. O., \& Vassend, O. (2018). Genetics, personality and wellbeing. A twin study of traits, facets and life satisfaction. Scientific Reports, 8, 12298.

Ryan, R. M., \& Deci, E. L. (2001). On happiness and human potentials: A review of research on hedonic and eudaimonic well-being. Annual Review of Psychology, 52, 141-166.

Ryff, C. D. (1989). Happiness is everything, or is it? Explorations on the meaning of psychological well-being. Journal of Personality and Social Psychology, 57, 1069-1081.

Sargent-Cox, K., Cherbuin, N., Morris, L., Butterworth, P., \& Anstey, K. J. (2014). The effect of health behavior change on self-rated health across the adult life course: A longitudinal cohort study. Preventive Medicine, 58, 75-80.

Schermelleh-Engel, K., Moosbrugger, H., \& Müller, H. (2003). Evaluating the fit of structural equation models: Tests of significance and descriptive goodness-of-fit measures. Methods of Psychological Research Online, 8(2), 23-74.

Schreiber, J. B., Nora, A., Stage, F. K., Barlow, E. A., \& King, J. (2006). Reporting structural equation modeling and confirmatory factor analysis results: A review. The Journal of Educational Research, 99(6), 323-338.

Seligman, M. E. P. (2008). Positive health. Applied Psychology, 57(s1), 3-18.

Södergren, M., Sundquist, J., Johansson, S., \& Sundquist, K. (2008). Physical activity, exercise and self-rated health: A population-based study from Sweden. BMC Public Health, 8, 352.

Sonnentag, S. (2003). Recovery, work engagement, and proactive behavior : A new look at the interface between nonwork and work. The Journal of Applied Psychology, 88(3), 518-528.

Sonnentag, S., \& Bayer, U. (2005). Switching off mentally. Journal of Occupational Health Psychology, 10(4), 393-414.

Steel, P., Schmidt, J., \& Shultz, J. (2008). Refining the relationship between personality and subjective wellbeing. Psychological Bulletin, 134(1), 138-161.

Steinmo, S., Hagger-Johnson, G., \& Shahab, L. (2014). Bidirectional association between mental health and physical activity in older adults: Whitehall II prospective cohort study.

Takeda, F., Noguchi, H., Monma, T., \& Tamiya, N. (2015). How possibly do leisure and social activities impact mental health of middle-aged adults in Japan?: An evidence from a national longitudinal survey. PLoS One, 10(10), e0139777.

Weiss, D. R., O'Loughlin, J. L., Platt, R. W., \& Paradis, G. (2007). Five-year predictors of physical activity decline among adults in low-income communities: A prospective study. The International Journal of Behavioral Nutrition and Physical Activity, 4(1), 2.

Wiese, C. W., Kuykendall, L., \& Tay, L. (2018). Get active? A meta-analysis of leisure-time physical activity and subjective well-being. The Journal of Positive Psychology, 13(1), 57-66.

Williams, T., Guerin, E., \& Fortier, M. (2014). Conflict between women's physically active and passive leisure pursuits: The role of self-determination and influences on well-being. Applied Psychology: Health and Well-Being, 6(2), 151-172.

Wolf, I. D., \& Wohlfart, T. (2014). Walking, hiking and running in parks: A multidisciplinary assessment of health and well-being benefits. Landscape and Urban Planning, 130, 89-103.

$\mathrm{Xu}$, Q., Anderson, D., \& Courtney, M. (2010). A longitudinal study of the relationship between lifestyle and mental health among midlife and older women in Australia: Findings from the healthy aging of women study. Health Care for Women International, 31(12), 1082-1096.

Zuzanek, J., Robinson, J. P., \& Iwasaki, Y. (1998). The relationships between stress, health, and physically active leisure as a function of life-cycle. Leisure Sciences, 20(4), 253-275.

Publisher's Note Springer Nature remains neutral with regard to jurisdictional claims in published maps and institutional affiliations. 